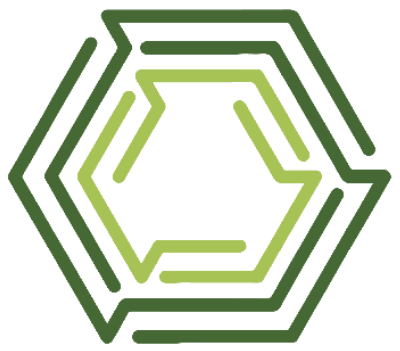

COINTER PDVAgro 2020

V CONGRESSO INTERNACIONAL DAS CIÊNCIAS AGRÁRIAS Edição $100 \%$ virtual | 02 a 05 de dezembro ISSN:2526-7701 | PREFIXO DOI:10.31692/2526-7701

\title{
ANIMAIS SILVESTRES EM CATIVEIRO: PERCEPÇÃO DO RISCO EPIDEMIOLÓGICO DA PROPAGAÇÃO DE ZOONOSES EM UMA COMUNIDADE RURAL DO SERTÃO CENTRAL PERNAMBUCO
}

\section{ANIMALES EN CAUTIVIDAD: PERCEPCIÓN DEL RIESGO EPIDEMIOLÓGICO DE PROPAGACIÓN DE ZOONOSIS EN UNA COMUNIDAD RURAL DEL SERTÃO PERNAMBUCO}

\author{
WILD ANIMALS IN CAPTIVITY: PERCEPTION OF THE ZOONOSIS \\ EPIDEMIOLOGICAL RISK IN A RURAL COMMUNITY OF THE CENTER \\ PERNAMBUCO
}

Apresentação: Comunicação Oral

Bianca Alves da Silva ${ }^{1}$; Dan Vítor Vieira Braga ${ }^{2}$

DOI: https://doi.org/10.31692/2526-7701.VCOINTERPDVAgro.0725

\begin{abstract}
RESUMO
A fauna silvestre é um dos recursos naturais que se tornou vítima da ganância humana. Atualmente, é fato comum nas famílias brasileiras, as pessoas terem em suas casas animais da fauna silvestre mantidos como animais de estimação. O presente trabalho teve o objetivo de descrever o cenário atual da criação de animais silvestres em cativeiro na comunidade rural do município de Verdejante, localizado no Sertão Central pernambucano e qual é a percepção da sociedade local a respeito dessa prática. Foram aplicadas entrevistas semiestruturadas à moradores de 30 residências na comunidade do distrito de Grossos, localizada $15 \mathrm{~km}$ ao sul da sede do município. Foram adotadas todas as medidas indicadas para prevenção da transmissão da Covid-19 (distanciamento mínimo entre pessoas e uso obrigatório de máscaras). Mais da metade dos entrevistados mantinham animais silvestres em casa. Ao todo foram identificados 19 indivíduos da fauna silvestre, sendo estes pertencentes a apenas duas classes zoológicas diferentes. Dentre as justificativas citadas pelos moradores para a manutenção destes animais em cativeiro, o canto, o valor sentimental e a beleza foram as mais frequentes. Quanto as formas de obtenção destes animais, foram citadas a captura direta na natureza, a compra e o recebimento como presente, sendo este último o mais frequente. Em relação à percepção quanto ao perigo/risco de manter animais silvestres nas residências, a maioria dos entrevistados desconhece completamente os riscos associados à manutenção desses animais em suas residências. Com o presente trabalho foi possível constatar que embora a prática seja ilegal é bastante comum na região, chamando a atenção do ponto de vista epidemiológico das zoonoses potencialmente transmitidas por esses animais à seres humanos e a animais domésticos.
\end{abstract}

Palavras-Chave: Animais silvestres, Zoonoses, Epidemiologia, Percepção Ambiental.

\section{RESUMEN}

1 Lic. em Ciências Biológicas, Faculdade de Ciências Humanas do Sertão Central (FACHUSC), bianca200alves@gmail.com

2 Lic. em Ciências Biológicas, Faculdade de Ciências Humanas do Sertão Central (FACHUSC), dan.braga@fachusc.com 
La fauna silvestre es uno de los recursos naturales que se ha convertido en víctima de la codicia humana. Actualmente, es un hecho común en las familias brasileñas, que las personas tienen animales de fauna salvaje mantenidos en sus hogares como mascotas. El presente trabajo tuvo como objetivo describir el escenario actual de la creación de animales silvestres en cautiverio en la comunidad rural del municipio de Verdejante ubicada en el Sertão Central de Pernambuco y cuál es la percepción de la sociedad local sobre esta práctica. Se aplicaron entrevistas semiestructuradas a residentes de 30 residencias de la comunidad distrital de Grossos, ubicada a $15 \mathrm{~km}$ al sur de la sede del municipio. Se adoptaron todas las medidas indicadas para evitar la transmisión del Covid-19 (distancia mínima entre personas y uso obligatorio de máscaras). Más de la mitad de los entrevistados tenían animales salvajes en casa. En total, se identificaron 19 individuos de la fauna silvestre, estos pertenecientes solo a dos clases zoológicas diferentes. Entre las justificaciones citadas por los vecinos para mantener a estos animales en cautiverio, el canto, el valor sentimental y la belleza fueron las más frecuentes. En cuanto a las formas de obtención de estos animales, se mencionaron la captura directa en la naturaleza, compra y recepción como obsequio, siendo esta última la más frecuente. En cuanto a la percepción del peligro / riesgo de tener animales salvajes en sus hogares, la mayoría de los entrevistados desconocen por completo los riesgos asociados con tener estos animales en sus hogares. Con el presente trabajo se pudo constatar que aunque la práctica es ilegal es bastante común en la región, llamando la atención desde el punto de vista epidemiológico de las zoonosis potencialmente transmitidas por estos animales a humanos y animales domésticos.

Palabras Clave: Animales salvajes, Zoonosis, Epidemiología, Percepción ambiental.

\section{ABSTRACT}

Wild fauna is one of the natural resources that has become a victim of human greed. Currently, it is a common fact in Brazilian families, that people have wild fauna animals kept in their homes as pets. The present work had the objective of describing the current scenario of the creation of wild animals in captivity in the rural community of the municipality of Verdejante located in the Central Sertão of Pernambuco and what is the perception of the local society regarding this practice. Semi-structured interviews were applied to residents of 30 residences in the Grossos district community, located $15 \mathrm{~km}$ south of the municipality's headquarters. All the measures indicated to prevent the transmission of Covid-19 (minimum distance between people and mandatory use of masks) were adopted. More than half of the interviewees kept wild animals at home. In all, 19 individuals from the wild fauna were identified, these belonging to only two different zoological classes. Among the justifications cited by residents for keeping these animals in captivity, singing, sentimental value and beauty were the most frequent. Regarding the ways of obtaining these animals, direct capture in nature, purchase and receipt as a gift were mentioned, the latter being the most frequent. Regarding the perception of the danger / risk of keeping wild animals in their homes, most interviewees are completely unaware of the risks associated with keeping these animals in their homes. With the present work it was possible to verify that although the practice is illegal it is quite common in the region, drawing attention from the epidemiological point of view of the zoonoses potentially transmitted by these animals to humans and domestic animals.

Keywords: Wild animals, Zoonoses, Epidemiology, Environmental Perception.

\section{INTRODUÇÃO}

O tráfico de animais é caracterizado pela busca e retirada dos animais de seus habitats naturais destinando-os à comercialização e exposição (GOMES et al, 2017). A mesma tem requintes de crueldade, já que muitos animais são mutilados (olhos furados, dentes arrancados ou cortados, unhas cortadas), sedados ou alcoolizados para diminuir o grau de agressividade (IAP, 2016).

Animais oriundos do tráfico tem a destinação aos colecionadores, à produção de 
medicamentos caseiros ou mortos para terem suas peles e outras partes do corpo retiradas e vendidas para fabricação de roupas e acessórios. Esta atividade, mesmo sendo proibida por lei, faz parte da cultura popular brasileira, sendo em determinadas regiões do país, um dos principais meios de vida de pessoas de baixa renda (DESTRO et al. 2017). Essa característica, somada ao extenso território do país e a baixa capacidade de fiscalização que os órgãos ambientais apresentam, resultam em um cenário preocupante de práticas criminosas relacionadas aos animais silvestres (DESTRO, 2012).

O Brasil é o país com a maior biodiversidade encontrada no mundo, com aproximadamente $20 \%$ das espécies mundiais, contendo 103.870 espécies de animais conhecidas ao longo de seu território e águas jurisdicionais brasileiras (MINISTREIO DOMEIO AMBIENTE, 2018). As instituições de proteção à fauna afirmam que o tráfico de animais silvestres é o terceiro maior tipo de tráfico no mundo, perdendo apenas para o narcotráfico e o tráfico de armas, movimentando no Brasil cerca de $\mathrm{R} \$ 10 \times 10^{6}$ por ano (IAP, 2016)

Além dos danos a biodiversidade é importante salientar que a presença de fauna silvestre em determinado local pode significar o surgimento de novos casos de doenças parasitárias em humanos, inclusive de leishmaniose visceral (LAINSON e RANGEL, 2005).

Muitas das doenças infecciosas humanas mais perigosas tiveram origem pela contribuição das aves e dos mamíferos, como por exemplo, a raiva, o ebola, a febre amarela, o tifo e a Síndrome da Imunodeficiência Adquirida (AIDS).

(WEISS ,2001)

Alguns desses patógenos com potencial zoonótico podem causar sérias doenças em animais silvestres, que muitas das vezes podem servir como reservatórios, disseminando as doenças, sem necessariamente apresentarem qualquer sintoma clínico. (ACHA E SZYFRES ,2003)

O presente trabalho tem o objetivo de descrever o cenário atual da criação de animais silvestres em cativeiro em uma comunidade rural do sertão central pernambucano e qual é a percepção da sociedade local a respeito dessa prática ilícita.

\section{FUNDAMENTAÇÃO TEÓRICA}

\section{Tráfico De Animais Silvestres}

Os seres humanos comercializam espécies animais desde tempos imemoriais: para uso como alimento, medicinal e para atividades culturais, científicas e esportivas. Entretanto, a expansão dos mercados e a crescente demanda por animais, combinadas com a evolução das 
técnicas de captura e o fácil transporte, estão causando a exploração de muitas espécies além dos níveis sustentáveis (BAILLIE. 2004).

No Brasil, o hábito de manter animais em cativeiro está presente de forma arraigada na maioria da população brasileira, em todas as classes sociais, o que torna difícil a educação das pessoas para a compreensão dos conceitos de ameaças e suas consequências para a Biodiversidade (SICK, 2001).

O tráfico de fauna silvestre é a retirada de espécimes da natureza para comercialização. Inicia-se com o indivíduo que reside junto ao ambiente natural, capturando e aprisionando os animais para vendê-los (IBAMA, 2006). O comércio ilegal está associado a problemas culturais, de educação, pobreza, falta de opções econômicas, pelo desejo de lucro fácil e rápido, e por status e satisfação pessoal de manter animais silvestres como de estimação (LIMA, 2007).

A expressão tráfico de animais silvestres no Brasil vem sendo aplicada extensivamente nas publicações englobando ilegalidades relacionadas à captura, ao comércio e manutenção de animais vivos (COSTA, 2017).

O contrabando de animais é o terceiro tipo de comércio ilegal mais rentável do mundo, perdendo apenas para o tráfico de drogas e o de armas. Calcula-se que essa atividade movimente, dez bilhões de dólares por ano, sendo mais de um bilhão originário do mercado nacional (ANDRADE, 2011)

No âmbito legal, a apreensão de animais em cativeiros ilegais, bem como a punição dos criminosos, depende das ações de fiscalização realizadas pelos órgãos responsáveis, como o IBAMA, Guarda Ambiental Nacional, Corpo de Guarda-Parques, Polícia Civil, Policia Militar e Policia Federal (RENCTAS, 2001)

\section{Legislação Específica}

De acordo com o Art. 29, $\S 3^{\circ}$ da Lei Federal no 9.605, de 12 de fevereiro de 1998, são espécimes da fauna silvestre todos aqueles pertencentes ás espécies nativas, migratórias e quaisquer outra, aquática ou terrestre, que tenham todo ou parte de seu ciclo de vida ocorrendo dentro dos limites de território brasileiro, ou águas jurisdicionais brasileiras (BRASIL, 1998).

Ainda de acordo com o supracitado artigo, "matar, perseguir, caçar, apanhar, utilizar espécimes da fauna silvestre [...], sem a devida permissão, licença ou autorização da autoridade competente é crime com pena de detenção de seis meses a um ano, e multa".

Entretanto, o Instituto Brasileiro do Meio Ambiente e dos Recursos Naturais Renováveis - IBAMA, neste caso a autoridade competente, poderá emitir licenças para criadores com finalidade científica, conservacionista ou mesmo comercial (ZOGO, 2008). 


\section{Riscos Associados A manutenção de Aniamis Silvestres em Cativeiro}

O contínuo aumento da introdução de animais silvestres como animais de companhia no mundo tem preocupado tanto os órgãos ambientais quanto os setores de saúde pública, por conta de as espécies hospedeiras exóticas e seus patógenos na natureza (pouco estudados) promover a chamada poluição patogênica, a qual tem ocasionado surtos de enfermidades zoonóticas em humanos, como por exemplo, a salmonelose (SCHLOEGEL., 2005).

Os animais silvestres, tanto em vida livre como em cativeiro, podem ser reservatórios e portadores de zoonoses de potencial significância na saúde pública, na conservação da vida silvestre e em aspectos econômicos (CLEAVELAND, 2001)

Os mecanismos mais importantes envolvidos nesta dispersão são o surgimento de novas amostras virais, por modificações genéticas, a transposição da barreira de espécie por um vírus e a disseminação viral a partir de um nicho ecológico.

É relevante mencionar a importância de animais silvestres de vida livre na cadeia de transmissão de zoonoses virais de grande potencial de dispersão mundial, como a febre

(SCHATZMAYR, 2001).

As aves podem ser potenciais transmissoras de doenças aos seres humanos. Entre 2008 e 2009, as principais etiologias diagnosticadas em Passeriformes, Piciformes, Psittaciformes e Strigiformes, foram as dos gêneros: Aspergillus, Candida, Capillaria, Chlamydophila, Eimeria, Haemoproteus, Isospora, Mycoplasma, Plasmodium, Sarcocystis, Staphylococcus, Tetrameres, Trichomonas (FERREIRA-JÚNIOR et al., 2010).

No caso dos mamíferos, as etiologias de potencial zoonótico em que eles são transmissores são: febre amarela, raiva, leptospirose, leishmanioses, febre maculosa entre outros.(MARVULO, 2006)

\section{METODOLOGIA}

\section{Área de estudo}

O presente trabalho foi desenvolvido no município de Verdejante (Figura 1) que está localizado no limite do estado de Pernambuco com o Estado do Ceará, pertencendo a mesorregião do Sertão Central. Possui uma população estimada de 9.430 habitantes no ano de 2010 e uma área de 476,034 $\mathrm{km}^{2}$ (INSTITUTO BRASILEIRO DE GEOGRAFIA E ESTATÍSTICA, 2010).

A pesquisa teve como área foco de estudo a comunidade rural do distrito de Grossos, localizada $15 \mathrm{~km}$ ao sul da sede do município. A comunidade possui uma população de aproximadament 750 habitantes. A principal fonte de renda da economia local é o serviço 
público municipal nas áreas de saúde, educação e transporte. A região geográfica do distrito dos Grossos pertence ao bioma Caatinga, fitofisionamia de Caatinga Arbustiva Arbórea Hiperxerófita, bima brasileiro endêmico, sendo o terceiro bioma mais degradado pelas atividades humanas (MINISTERIO DO MEIO AMBIENTE,2003).

Figura 01: Localização geográfica da área de estudo, Município de Verdejante, Pernambuco, Brasil.

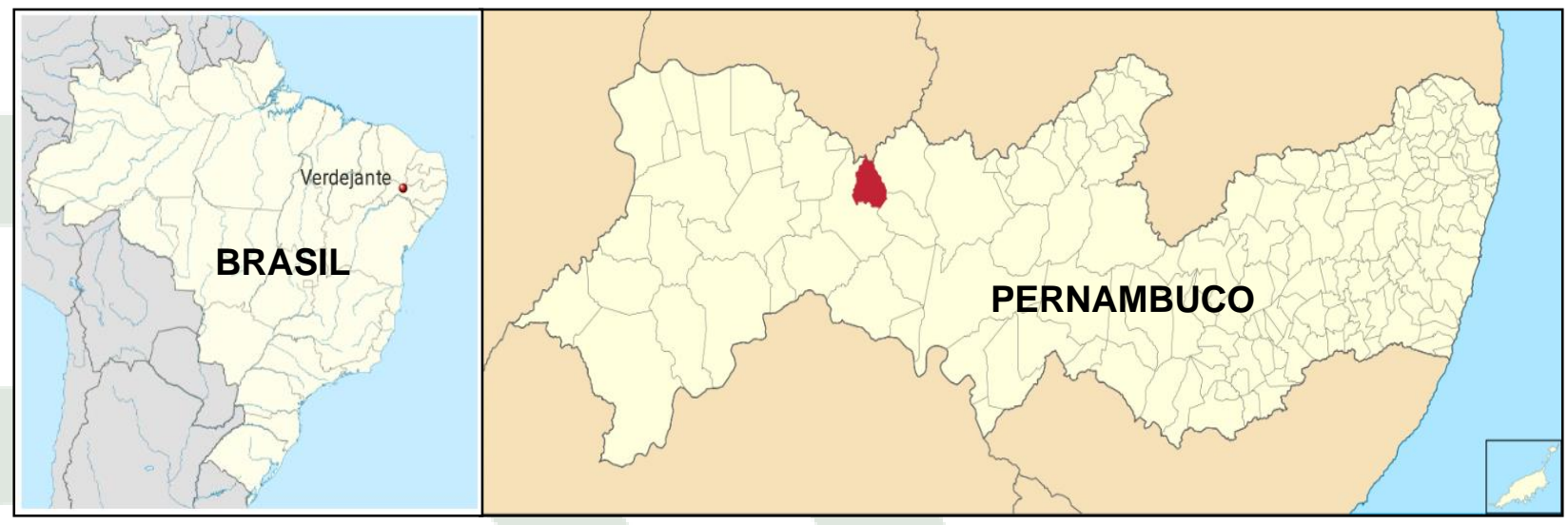

Fonte: Própria Modificado de Wikipédia (2020)

\section{Método}

A presente pesquisa qualitativa trata-se de um estudo de caso, conduzido no mês de agosto a outubro de 2020, sendo a coleta de dados realizada através de uma entrevista semiestruturada aplicada à moradores de 30 residências escolhidas aleatoriamente na comunidade alvo do estudo. Devido ao cenário global pandêmico, durante a coleta das informações foram adotadas todas as medidas indicadas para prevenção da transmissão da Covid-19 (distanciamento mínimo entre pessoas de 1,5m e uso obrigatório de máscaras) de forma a salvaguardar à saúde do pesquisador e dos informantes.

A entrevista consistiu de sete perguntas a respeito da criação de animais silvestres em cativeiro nas residências e da percepção acerca das zoonoses potencialmente transmitidas por esses animais aos moradores das residências e a seus animais domésticos. As questões foram relacionadas à forma em que esses animais foram adquiridos, as diferentes espécies mantidas nas residências, a quantidade de indivíduos que estavam em posse do morador, o tempo de posse de cada animal e, se o informante tinha a percepção de que algum daqueles animais oferecia algum risco a saúde do morador e de seus animais domésticos. Por ser uma prática tipificada como crime ambiental (Lei Federal $\mathrm{n}^{\circ}$ 9.605/1998), as entrevistas foram realizadas de forma a preservar a identidade dos informantes. 


\section{RESULTADOS E DISCUSSÃO}

Foram identificados um total de 19 indivíduos, pertencentes a oito espécies nativas da fauna silvestre do bioma Caatinga, sendo mantidos em cativeiro nas residências analisadas (Figura 2).

Figura 2: Frequência relativa (\%) dos animais da fauna silvestre mantidos em cativeiro identificados nas residências localizadas no Distrito de Grossos, Verdejante/PE.

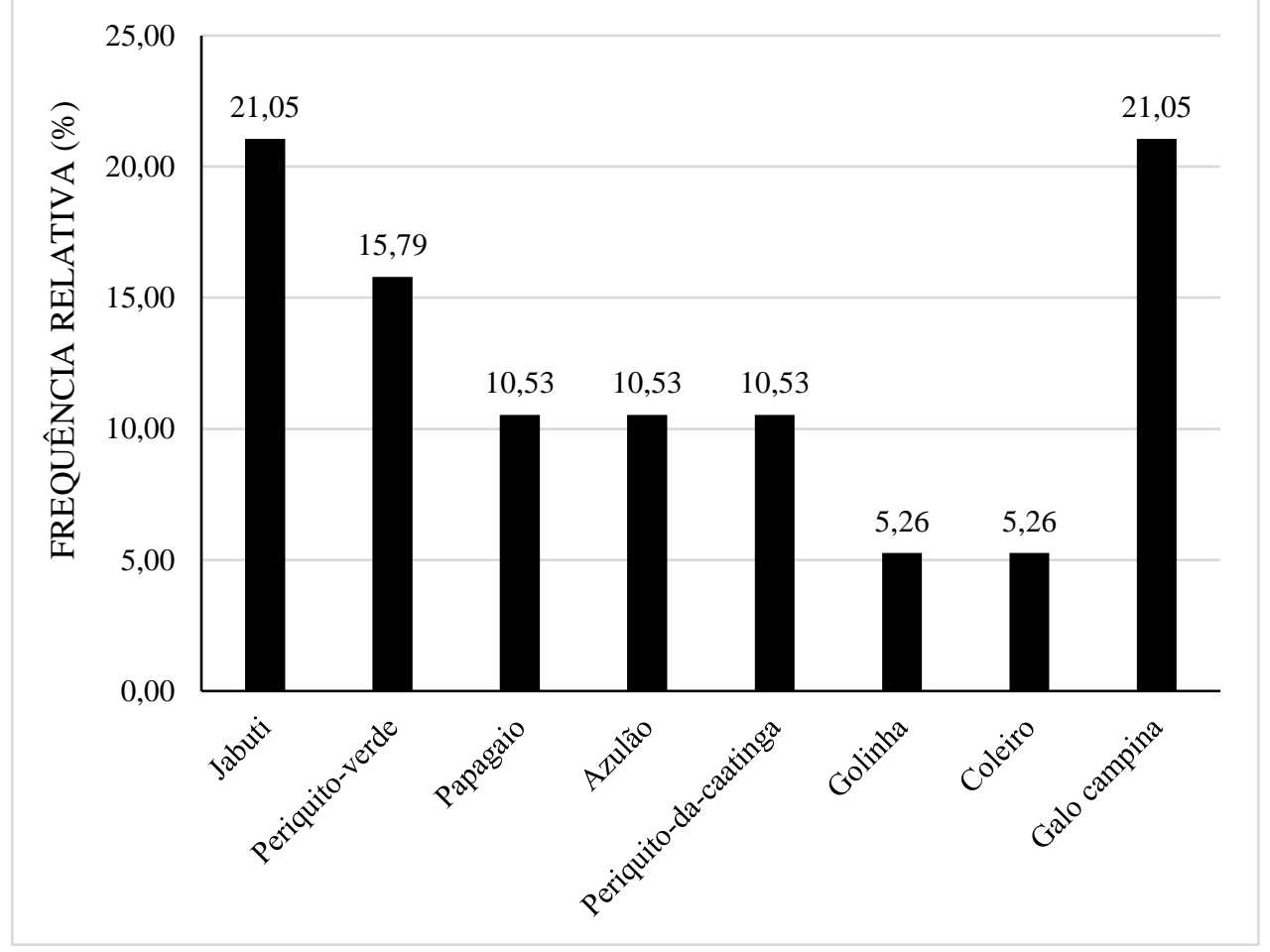

Fonte: Própria.(2020)

As nove espécies se concentraram em apenas duas classes de animais, Reptilia e Aves, havendo predominância desta última (Aves). As residências inventariadas possuíam pelo menos uma espécie de Ave mantida em cativeiro e, das nove espécies silvestres mantidas em cativeiro, apenas o Jabuti não pertence a Classe Aves (Quadro 1). Esses dados se assemelham com o estudo realizado por Pires et al. (2015), onde estas duas classes predominaram entre os animais mantidos em cativeiro em moradias localizadas na zona urbana da cidade de Verdejante/PE. 
Quadro 1: Animais da fauna silvestre mantidos em cativeiro identificados nas residências localizadas no Distrito de Grossos, Verdejante/PE.

\begin{tabular}{|c|c|c|c|c|}
\hline CLASSE & FAMILIA & ORDEM & ESPÉCIE & NOME VERNACULO \\
\hline \multirow{7}{*}{ Aves } & Emberizidae & Passeriformes & $\begin{array}{c}\text { Sporophila caerulescens } \\
\text { (Vieillot, 1823). }\end{array}$ & Coleiro \\
\hline & Fringillidae & Passeriformes & $\begin{array}{c}\text { Cyanoloxia brissonii brissonii } \\
\text { (Lichtenstein, 1823) }\end{array}$ & Azulão \\
\hline & & & $\begin{array}{l}\text { Amazona aestiva } \\
\text { (Linnaeus, 1758) }\end{array}$ & Papagaio-verdadeiro \\
\hline & \multirow[t]{2}{*}{ Psittacidae } & \multirow[t]{2}{*}{ Psitaciformes } & $\begin{array}{c}\text { Brotogeris tirica } \\
\text { (Gmelin, 1788) }\end{array}$ & Periquito-verde \\
\hline & & & $\begin{array}{l}\text { Eupsittula cactorum } \\
\text { (Kuhl, 1820) }\end{array}$ & Periquito-da-caatinga \\
\hline & \multirow{2}{*}{ Thraupidae } & Passeriformes & $\begin{array}{l}\text { Sporophila albogularis } \\
\text { (Cabanis, } 1847)\end{array}$ & Golinha \\
\hline & & Passeriformes & $\begin{array}{l}\text { Paroaria dominicana } \\
\quad \text { (Linnaeus, 1758) }\end{array}$ & Galo campina \\
\hline Reptilia & Testudinidae & Testudinata & $\begin{array}{l}\text { Chelonoidis carbonaria } \\
\text { (Spix, 1824) }\end{array}$ & Jabuti \\
\hline
\end{tabular}

Fonte: Própria (2020).

Em relação aos motivos para manter os indivíduos em cativeiro, o canto foi o mais citado pelos moradores, também as aves obtiveram um índice de criação maior, seguido do valor sentimental (Figura 03).

Figura 03: Frequência relativa dos diferentes motivos alegados pelos informantes para justificar a manutenção das espécies em cativeiro.

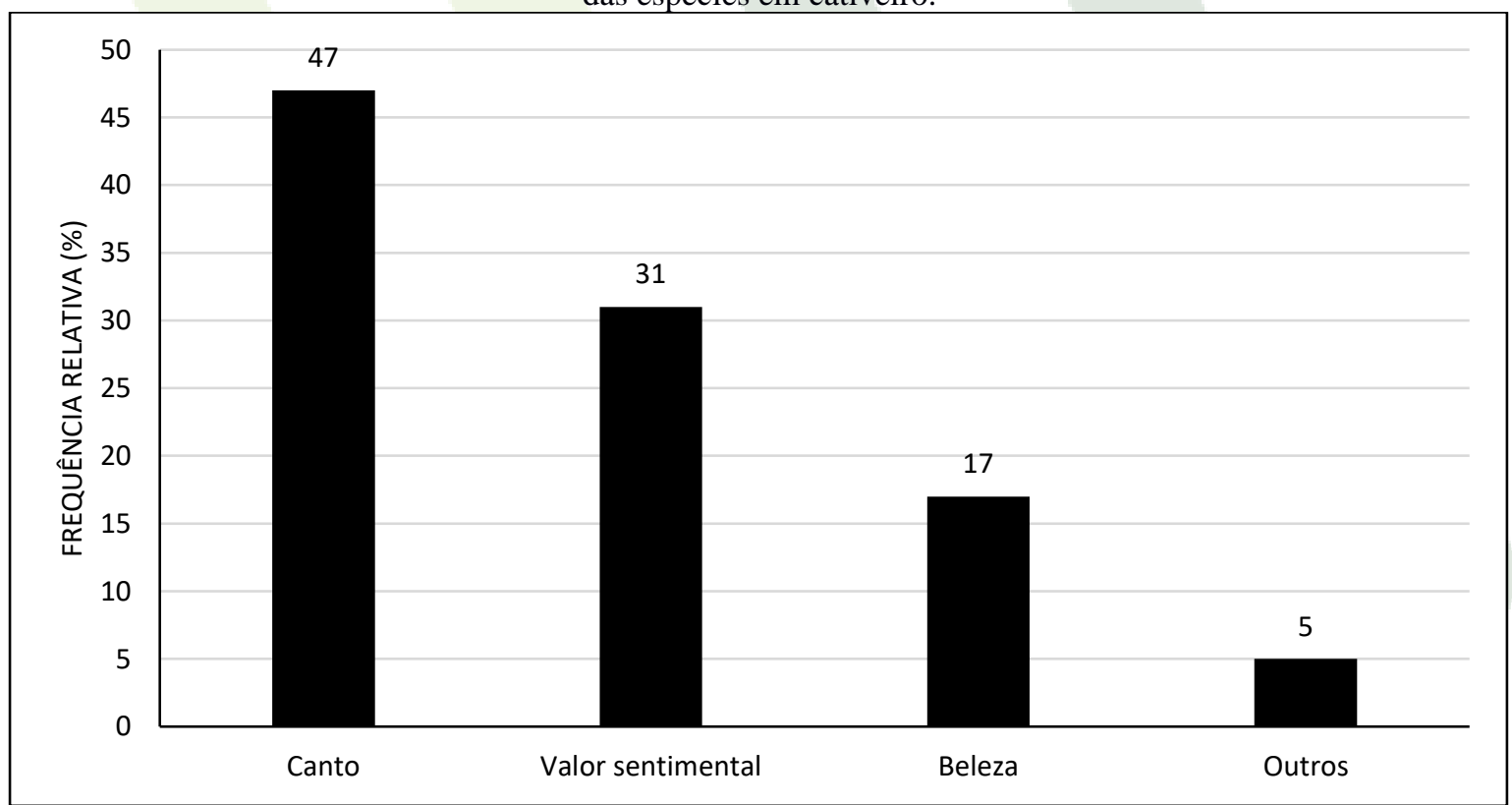

Fonte: Própria (2020). 
Quando indagado sobre a origem dos animais a maioria dos moradores responderam que ganharam de presente, e a senda forma de obtenção mais citada foi a captura das espécies na natureza (Figura 04). Estes dados corroboram com NUNES (2014) que em pesquisa na comunidade rural poço do bezerro e no Bairro Padre José Maria zona urbana do município de Verdejante/PE, também constatou que a atividade do tráfico de animais silvestres tem um baixo índice na região.

Figura 04: Frequência observada das formas de aquisição dos animais silvestre mantidos em cativeiro.

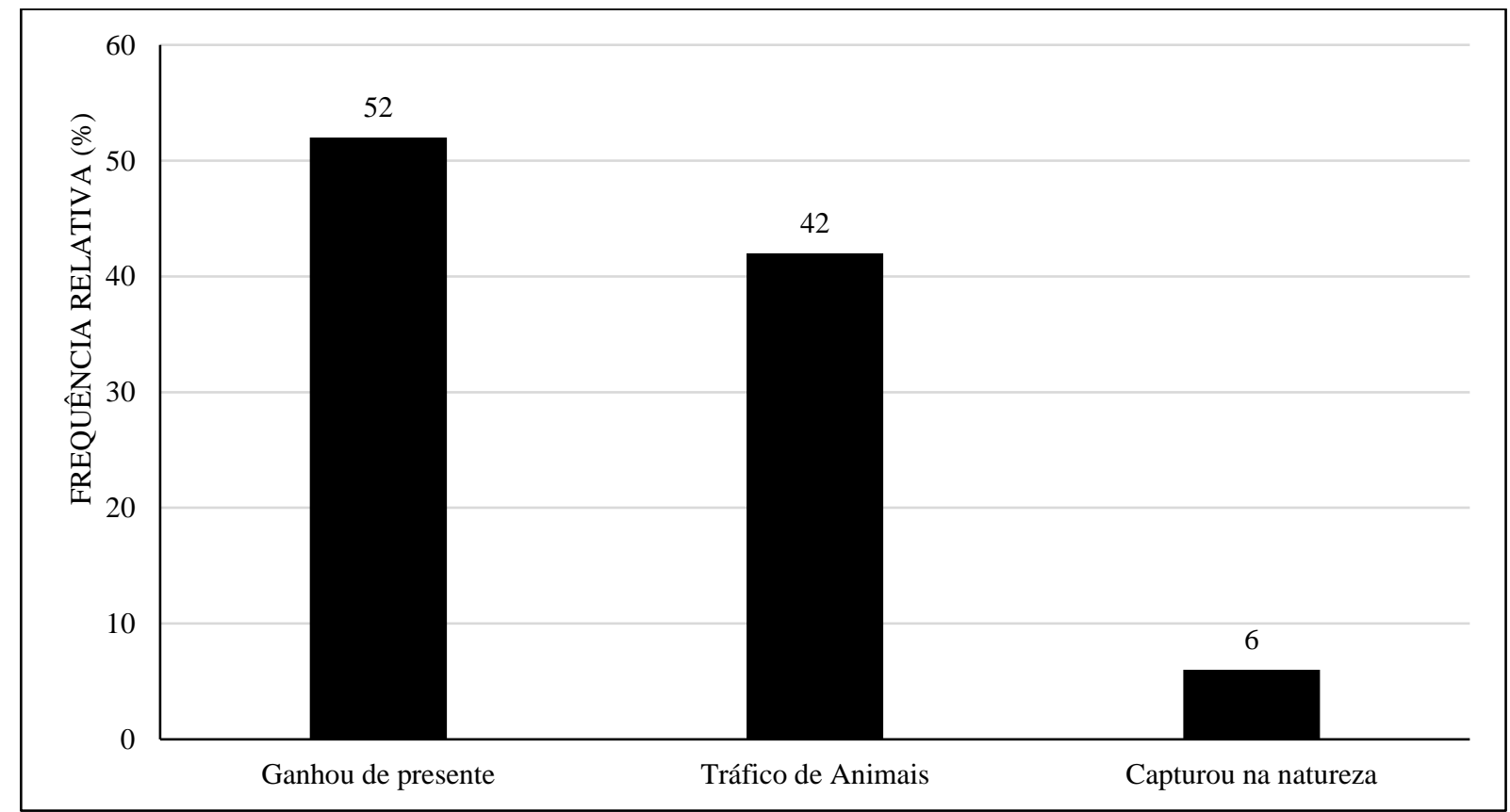

Fonte: Própria (2020).

Em relação aos perigos de manter animais silvestres em cativeiro, a maioria dos entrevistados respondeu que a criação desses animais não oferece nenhum risco a saúde das pessoas que co-habitam as residências, mas três entrevistados relataram sua preocupação com a possibilidade de eventuais acidentes envolvendo a mordida do animal. Porém, sem fazer a conexão com o potencial de transmissão de doenças às pessoas nas residências (Figura 05). Nenhum entrevistado demonstrou perceber os reais riscos para a transmissão de zoonoses à animais domésticos e também não souberam identificar qual seriam as doenças, suas formas de contágio e de prevenção.

As aves e repteis podem ser potenciais transmissoras de doenças aos seres humanos e apesar de não reconhecido pelos moradores a salmonelose é causada por bactérias do gênero Salmonella transmitida pelas aves e repteis, fato é que o consumo de animais silvestres exacerbado e sem controle na China resultou na disseminação do Covid-19 que de acordo com estudos surgiu nos mercados de animais silvestres do país, este vírus tomou grandes proporções 
é se tornou uma pandemia.

Figura 05: Formas descritas de risco ou perigo potencial advindo dos animais silvestres mantidos nas residências conforme a percepção dos entrevistados

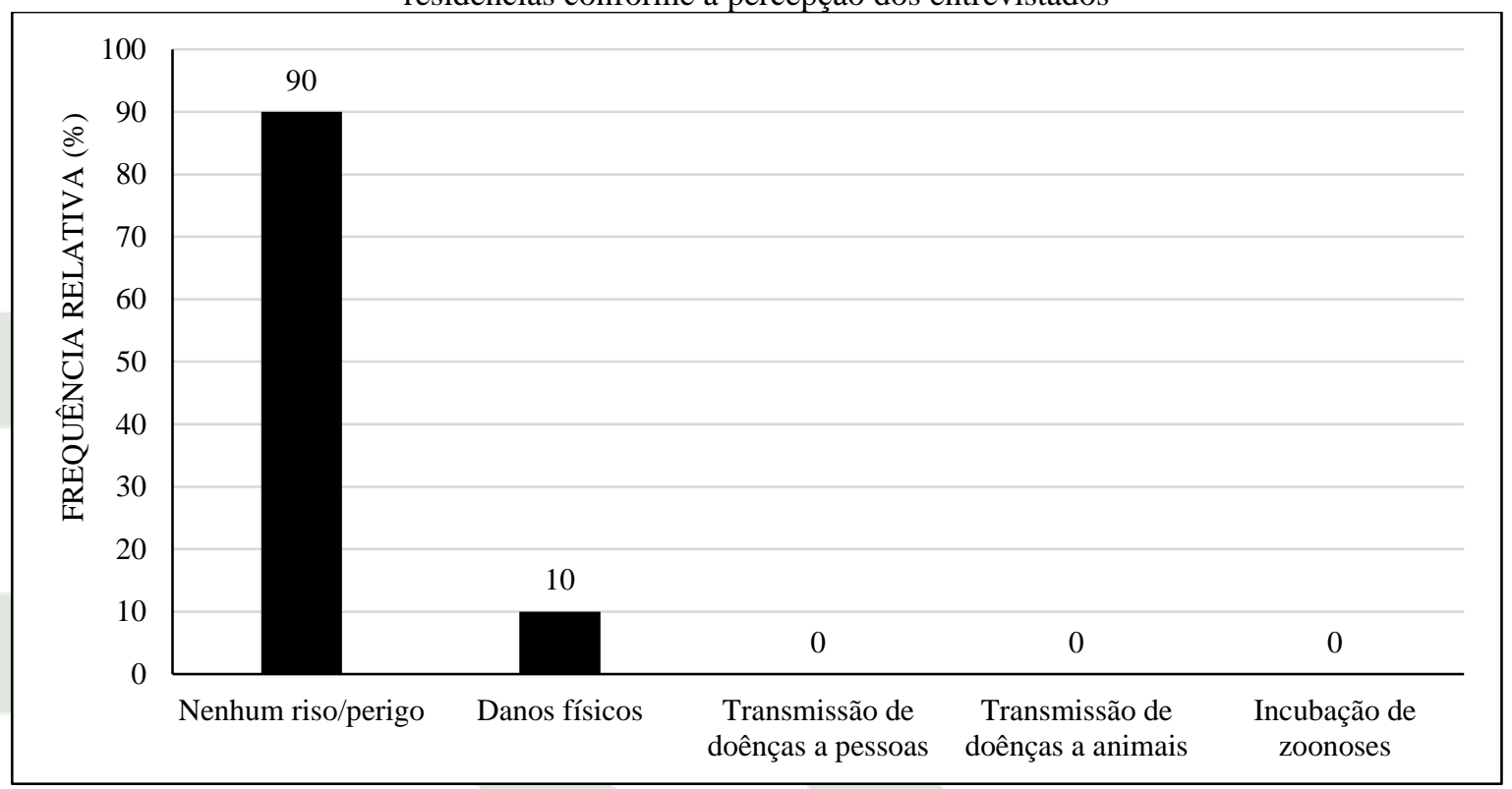

Fonte: Própria (2020).

Conforme os entrevistados, houve uma grande variação do tempo em que esses animais são mantidos em cativeiro. O tempo de cativeiro variou de um mês a seis anos, com uma média de 2 anos e 8 meses. Todos os entrevistados admitem ter conhecimento que a manutenção de animais em cativeiro configura crime ambiental, porém mesmo assim, eles mantêm essa prática como um hobby culturalmente perpetuado entre as pessoas da comunidade alvo do estudo.

Devido a falta de fiscalização e de informação a respeito das consequências de manter estes animais em cativeiro este hobby vem sendo passado culturalmente. O consumo também tem contribuído no fato dos moradores manter esses animais em casa já que o comercio da carne é uma atividades rentável.

\section{CONCLUSÕES}

Com a presente pesquisa foi possível constatar que, embora a manutenção de animais silvestres seja reconhecida como ilegal pelas pessoas entrevistadas, ela é uma prática bastante comum na comunidade estudada e não há a preocupação com uma possível autuação dos órgãos de fiscalização, nem com os riscos à saúde da população.

Outro fato a ser evidenciado é que, mesmo com a pandemia da COVID-19 e sua ligação direta com o tráfico e a manutenção de animais silvestres nos mercados de preparação e comercialização de alimentos na China, a população da comunidade em estudo não desenvolveu a percepção que a manutenção dessa prática gera grandes potenciais de 
disseminação de novas zoonoses para pessoas e para os animais domésticos de interesse econômico. É notória a necessidade de conscientização dos moradores sobre os riscos epidemiológicos associados a esta prática.

\section{REFERÊNCIAS}

ACHA, P.N.; SZYFRES, B. Zoonosis y enfermedades transmisibles comunes al hombre y a los animales, $3^{\text {a }}$ ed., Washington: Organización Panamericana de la Salud. 2003. 989p.

ANDRADE, H.B.D. 2011. A ameaça do tráfico de animais silvestres no Brasil: o Caso da Arara-azul e do Mico-leão-dourado. Monografia (Licenciatura em Ciências Biológicas) Consórcio Setentrional de Educação a Distância, Universidade de Brasília - DF, Universidade Estadual de Goiás - GO, Brasília 26p.

BAILLIE, J. E. M.; HILTON-TAYLOR, C.; STUART, S. N. IUCN. Red List of Threatened Species. A Global Species Assessment. IUCN, Gland, Switzerland and Cambridge, UK, 2004. $191 \mathrm{p}$.

BRASIL. Lei Federal $\mathbf{n}^{\mathbf{0}}$ 9.605, de 12 de fevereiro de 1998. Lei dos Crimes Ambientais. Presidência da República Federativa do Brasil. Disponível em: < http://www.planalto.gov.br/ccivil_03/leis/19605.htm>. Acesso em: 27 de maio. 2020.

CLEAVELAND, S.; LAURENSON, M.K.;TAYLOR, L.H. Diseases of humans and their domestic mammals: pathogen characteristics, host range and the risk of emergence. Philosophical Transactions of the Royal Society Biological Sciences, London, n. 356, p. $991-$ 999, 2001.

COSTA, F.J.B. 2017. Ciência contra o Tráfico: Avanços no Combate ao Comércio Ilegal de Animais Silvestres. João Pessoa, IMPRELL. 250p

DESTRO, G.F.G.; PIMENTEL, T.L; SABAINI, R.M.; BORGES, R.C.; BARRETO, R. (2017) Esforços para o combate ao tráfico de animais silvestres no Brasil (Trad. do original em inglês).

http://www.ibama.gov.br/sophia/cnia/periodico/esforcosparaocombateaotraficodeanimais.pdf. Acesso em: 10/06/2017.

G.; BARRETO, R.; SABAINI, R. M.; BORGES, R. C.; PIMENTEL, T. L. Efforts to combat wild animals trafficking in Brazil. INTECH Open Access Publisher, 2012.

FERREIRA-JÚNIOR, F.C.; ARAÚJO, A.V.; CARVALHAES, A.G. et al. Doenças diagnosticadas em aves silvestres e exóticas no Setor de Doenças das Aves da EV-UFMG nos anos de 2008 e 2009. XVIII SEMANA DE INICIAÇÃO CIENTÍFICA, 2010.

GOMES, et al. Esforços para o combate ao tráfico de animais silvestres no Brasil. Disponível

em:<http://www.icmbio.gov.br/revistaeletronica/index.php/BioBR/article/view/9>: Acesso em: 14 mai. 2019

IAP ,2006. Principais Ameaças à Fauna. Rede Pró-Fauna. Instituto Ambiental do Paraná. 
IBAMA - Instituto Brasileiro do Meio Ambiente e dos Recursos Naturais Renováveis Disponível em: <http://www.ibama.gov.br/> Acesso em 17 out. 2006 10:40:30.

IBGE - Instituto Brasileiro de Geografia e Estatística. Verdejante, panorama. 2010. Disponível em : http://cidades.ibge.gov.br/brasil/pe/verdejante/panorama. Acesso em: 30 set.2020. 09:57.

LIMA, G. G. B. A conservação da fauna e da flora silvestres no Brasil: a questão do tráfico ilegal de plantas e animais silvestres e o desenvolvimento sustentável. Rev. Jur., Brasília, v. 9, n. 86, p.134150, ago./set., 2007

MINISTÉRIO DO MEIO AMBIENTE - MMA. Biodiversidade. Disponível em: http://www.mma.gov.br/biodiversidade/convencao-da-diversidade-biologica Acesso em : 24 de maio de 2018.

PIRES, G. A.; RODRIGUES, S. F. da C.; MACEDO, K. R.; ANDRADE, A. M. F. de; FARIKOSKI, I. O.; FREITAS, H. J. de; RIBEIRO, V. M. F. Tráfico de animais silvestres e seus produtos no extremo oeste brasileiro. Arq. Ciênc. Vet. Zool. UNIPAR, Umuarama, v. 18, n. 4, p. 241-245, out./dez. 2015

RENCTAS. $1^{\circ}$ Relatório Nacional sobre o tráfico de Fauna Silvestre. Brasília, 108p. 2001.

SCHATZMAYR, H.G. Viroses emergentes e reemergentes. Cadernos de Saúde Pública, Rio de Janeiro, v. 17 (Suplemento) p. 209-213, 2001

SCHLOEGEL, L.M.; DASZAK, P.; NAVA, A. Medicina da Conservação: buscando causas e soluções práticas para doenças infecciosas emergentes. Natureza \& Conservação, Curitiba, v. 3, n. 2, p. 29-41, 2005.

SICK, H. Ornitologia Brasileira. Rio de Janeiro: Nova Fronteira, 3 ed., 2001. 912p.

ZOGO, 2008. Animais da Fauna Silvestre mantidos como animais de estimação. 39 p, Dissertação (Especialização em Educação Ambiental) - Programa de Pós Graduação em Educação Ambiental - Universidade Federal de Santa Maria Centro de Ciências Rurais. 2008.

GUBA, E. G.; LINCOLN, Y. S. Fourth generation evaluation. Newbury Park, London, New Delhi: Sage, 1989.

HOFFMAN, J. Avaliação mediadora: uma prática em construção da pré-escola à universidade. Porto Alegre: Mediação, 2001.

LAINSON, R.; RANGEL, E.F. Lutzomyia longipalpis and the eco-epidemiology of American visceral leishmaniasis, with particular reference to Brazil - A Review. Memórias do Instituto Oswaldo Cruz, Rio de Janeiro, v. 100, n. 8, p. 811-827, 2005.

LIMA, K. S. Compreendendo as concepções de avaliação de professores de física através da teoria dos construtos pessoais. Recife, 2008. 163 p. Dissertação (Ensino das Ciências). Departamento de Educação, UFRPE, 2008. 
SALES, E. S.; MONTEIRO, I. G. S.; LIMA, K. S. Formação de professor, diretrizes da Educação brasileira para o ensino de Química e Avaliação: saberes docentes essenciais à formação docente. In: VII Colóquio Internacional Educação e Contemporaneidade, 2013, São Cristóvão - SE. Anais do Colóquio Internacional Educação e Contemporaneidade, 2013.

NARDI, R.; CORTELLA, B. S. C. Formação de professores de Física: das intenções legais ao discurso dos formadores. In: XVI Simpósio Nacional de Ensino de Física, 2005, Rio de Janeiro. Caderno de Resumos. São Paulo - SP: Sociedade Brasileira de Física, 2005. v. 1. p. 175-175, 2005.

NUNES 2014. Hábitos culturais x biologia da conservação :Fauna silvestre mantida em cativeiro. Salgueiro, 35p. monografia (licenciatura em ciências biológicas) - faculdade de ciências humanas do sertão central, 2014.

WEISS, R.A. Animal origins of human infectious disease. Philosophical Transactions of the Royal Society Biological Sciences, London, v. 356, n. 1410, p. 957-977, 2001. 